\title{
Pharmacokinetics of Morphine and its Metabolites in Neonates with Hypoxic- Ischemic Encephalopathy During and After Therapeutic Hypothermia
}

\section{Wilhelmina Kinderziekenhuis}

Contact: Ifavie@umcutrecht.nl

Authors: Laurent M.A. Favié1,2, Floris Groenendaal2,3, Carin M.A. Rademaker1, Timo R. de Haan ${ }^{4}$, Toine C.G. Egberts $^{1,5}$, Frank van Bel2,3, Marcel P.H. van den Broek ${ }^{1,6}$, Alwin D.R. Huitema ${ }^{1,7}$, and the PharmaCool Study Group

${ }^{1}$ Department of Clinical Pharmacy, University Medical Center Utrecht, the Netherlands; ${ }^{2}$ Department of Neonatology, Wilhelmina Children's Hospital, University Medical Center Utrecht, the Netherlands; ${ }^{3}$ Brain Center Rudolf Magnus, University Medical Center Utrecht, the Netherlands; ${ }^{4}$ Department of Neonatology, Emma Children's Hospital, Academic Medical Center, Amsterdam, the Netherlands; ${ }^{5}$ Department of Pharmaco-epidemiology and Clinical Pharmacology, Faculty of Science, Utrecht University, the Netherlands; ${ }^{6}$ Department of Pharmacy, St. Antonius Hospital, Nieuwegein, the Netherlands and ${ }^{7}$ Department of Pharmacy \& Pharmacology, Netherlands Cancer Institute, Amsterdam, the Netherlands

Background: Morphine is a routinely used drug in neonates undergoing therapeutic hypothermia $(\mathrm{TH})$ as treatment for hypoxic-ischemic encephalopathy (HIE). Pharmacokinetics (PK) and optimal dosing of morphine in this population, however, are still largely unknown.

Objective: To examine the effect of hypothermia on the PK of morphine in neonates with HIE and to develop PK based dosing guidelines.

\section{Results}

\section{Table 1: Patient characteristics}

\begin{tabular}{|c|c|}
\hline Parameter & $\mathbf{N}=244$ \\
\hline Gestational age (wk; mean \pm sd) & $38.8 \pm 1.6$ \\
\hline Birth weight (g; mean $\pm \mathrm{sd}$ ) & $3,428 \pm 613$ \\
\hline Male (n, \%) & $150(61.5)$ \\
\hline $\mathrm{pH}($ median, IQR)* & $6.96(6.80-7.09)$ \\
\hline Base Excess (mmol/L, median, IQR) ${ }^{*}$ & $-17(-12--21.9)$ \\
\hline Lactate $\left(\mathrm{mmol} / \mathrm{L}\right.$, median, IQR) ${ }^{*}$ & $13.6(9.0-18.2)$ \\
\hline Thompson score (median, IQR)\# & $9.5(8.0-12.0)$ \\
\hline Mortality (n, \%) & $58(23.8)$ \\
\hline \multicolumn{2}{|c|}{$\begin{array}{l}\text { *Value measured in umbilical cord blood or, if unavailable, form arterial } \\
\text { or venous blood within } 1 \mathrm{~h} \text { after birth } \\
\text { "Highest score before start of hypothermia }\end{array}$} \\
\hline \multicolumn{2}{|c|}{$\begin{array}{l}\text { Morphine was administered as continuous infusion } \\
\text { with or without a loading dose. Morphine plasma } \\
\text { levels ranged between } 10 \text { and } 371 \mu \mathrm{g} / \mathrm{L} \text { (Figure } 1 \text { ). }\end{array}$} \\
\hline
\end{tabular}

Figure 1: Observed morphine plasma concentrations

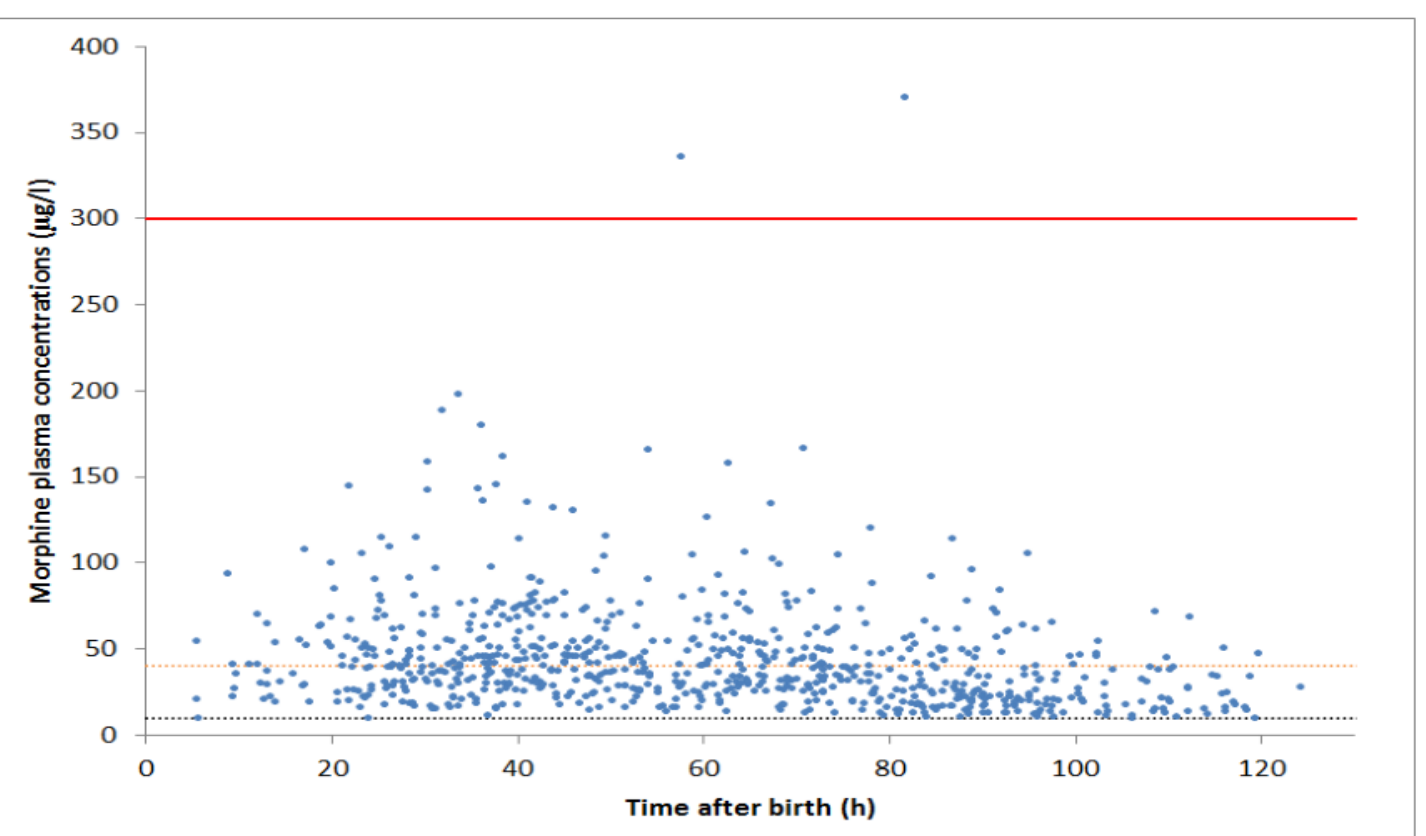

Methods: Data was collected in two multicentre prospective cohort studies. (Near-)term neonates who received morphine while treated with $\mathrm{TH}$ for HIE were eligible for inclusion. Once daily plasma samples were obtained during both hypothermia and normothermia. Morphine concentrations were analyzed using an LC-MS/MS method.

Pharmacokinetic analyses were performed using NONMEM (version 7.3).

\section{Results (continued)}

A population pharmacokinetic model was developed; morphine clearance was dependent on gestational age, postnatal age and body temperature. Morphine clearance during hypothermia was reduced by $15.8 \%$ compared to normothermia. A loading dose of 50 $\mu \mathrm{g} / \mathrm{kg}$ followed by continuous infusion of $5 \mu \mathrm{g} / \mathrm{kg} / \mathrm{h}$ resulted in morphine plasma concentrations in the desired range (10-40 $\mu \mathrm{g} / \mathrm{L}$, Figure 2$)$.

\section{Figure 2: Simulated morphine plasma concentrations of the proposed dosing regimen}

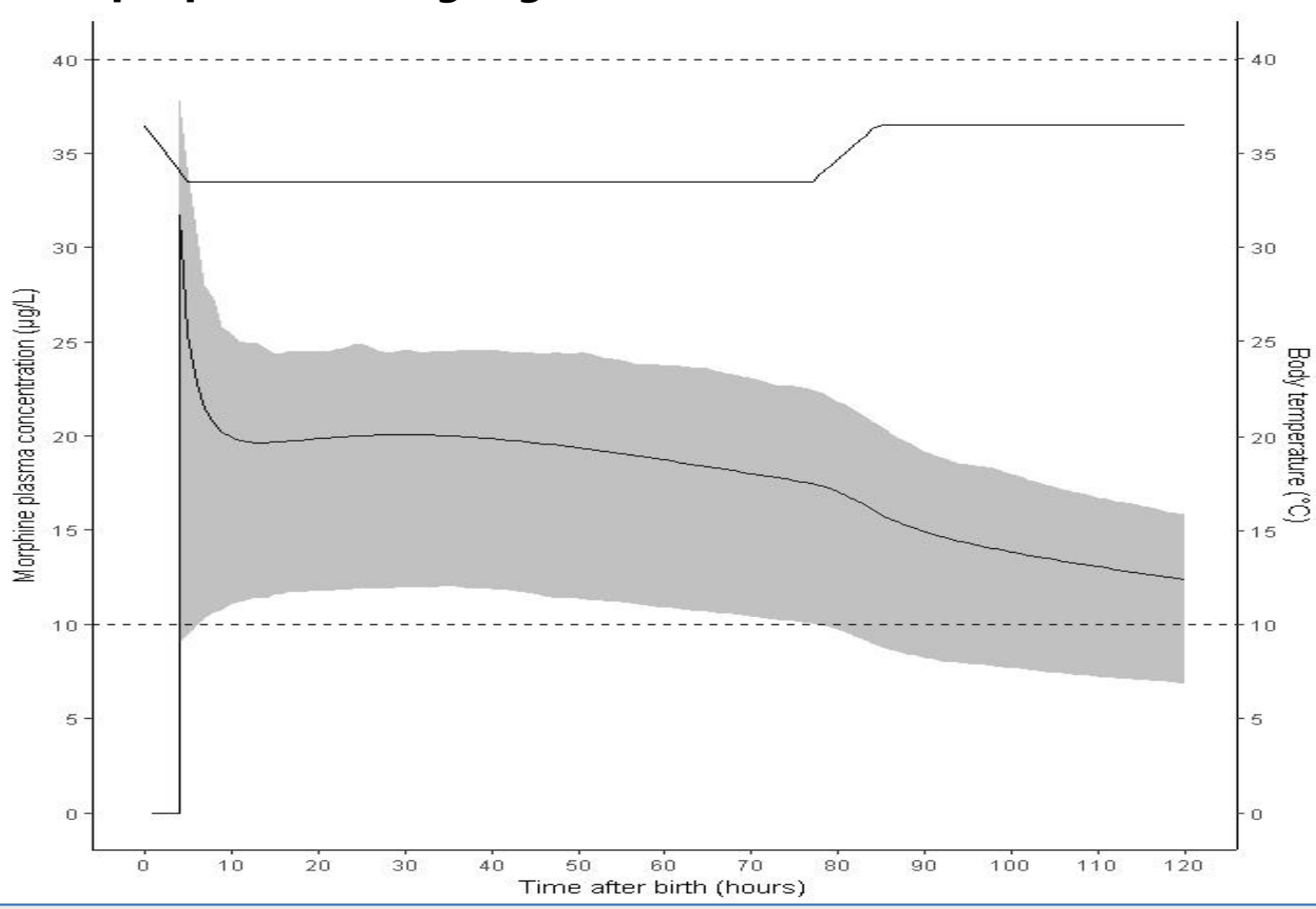

Conclusion

- Clearance of morphine is reduced in neonates during hypothermia compared to normothermia.

- A relatively low dose of $5 \mu \mathrm{g} / \mathrm{kg} / \mathrm{h}$ preceded by a loading dose of $50 \mu \mathrm{g} / \mathrm{kg}$ is recommended to avoid morphine overexposure.

- Due to high interpatient variability, higher doses might be necessary in individual patients. 